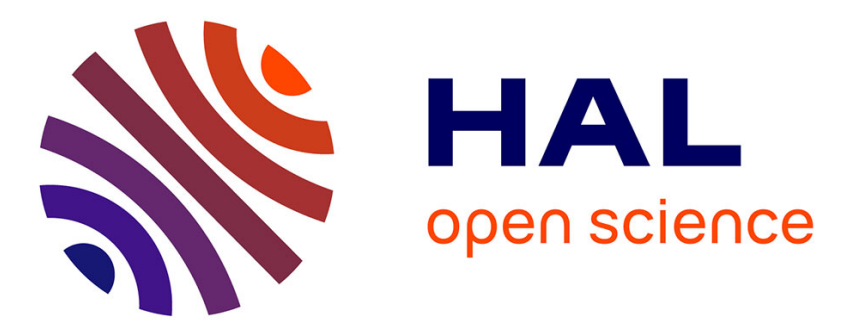

\title{
From pictures to extended finite elements: extended digital image correlation (X-DIC)
}

\author{
Julien Réthoré, Stéphane Roux, François Hild
}

\section{To cite this version:}

Julien Réthoré, Stéphane Roux, François Hild. From pictures to extended finite elements: extended digital image correlation (X-DIC). Comptes Rendus Mécanique, 2007, 335, pp.131-137. 10.1016/j.crme.2007.02.003 . hal-00199381

\section{HAL Id: hal-00199381 \\ https://hal.science/hal-00199381}

Submitted on 18 Dec 2007

HAL is a multi-disciplinary open access archive for the deposit and dissemination of scientific research documents, whether they are published or not. The documents may come from teaching and research institutions in France or abroad, or from public or private research centers.
L'archive ouverte pluridisciplinaire HAL, est destinée au dépôt et à la diffusion de documents scientifiques de niveau recherche, publiés ou non, émanant des établissements d'enseignement et de recherche français ou étrangers, des laboratoires publics ou privés. 


\title{
From pictures to extended finite elements: Extended digital image correlation (X-DIC)
}

\section{Corrélation d'images numériques étendue (CINÉ)}

\author{
Julien Réthoré ${ }^{\mathrm{a}}$ Stéphane Roux ${ }^{\mathrm{b}}$ François Hild ${ }^{\mathrm{a}}$ \\ ${ }^{a}$ LMT-Cachan, ENS de Cachan / CNRS UMR 8535 / Université Paris 6 \\ 61 Avenue du Président Wilson, F-94235 Cachan Cedex, France \\ b Surface du Verre et Interfaces, UMR CNRS/Saint-Gobain, 39 Quai Lucien Lefranc, 93303 Aubervilliers Cedex, France
}

\begin{abstract}
An image correlation algorithm accounting for discontinuities is proposed. It is based on a decomposition of the displacement field onto a regular finite element basis supported by a uniform mesh, enriched with suitable functions to describe accurately discontinuities, paralleling recent developments of extended finite elements. This algorithm is applied to a bolted assembly where interface slip is observed upon loading.

\section{Résumé}

Un algorithme de corrélation d'images numériques capable de rendre compte de discontinuités est introduit. Il est fondé sur une décomposition du champ de déplacement sur une base régulière de type éléments finis supportés par un maillage homogène, enrichie par des fonctions de base adaptées aux discontinuités, suivant les développements récents des éléments finis étendus. Cet algorithme est appliqué à l'étude d'un assemblage boulonné où un glissement est mobilisé sous charge.
\end{abstract}

Key words: Rupture; Discontinuity; Photomechanics

Mots-clés : Rupture; Discontinuité; Photomécanique

Email addresses: rethore@lmt.ens-cachan.fr (Julien Réthoré), stephane.roux@saint-gobain.com (Stéphane Roux), hild@lmt.ens-cachan.fr (François Hild). 


\section{Version française abrégée}

Les méthodes de mesure de champ sont particulièrement attractives lorsque l'on souhaite analyser des phénomènes localisés (e.g., discontinuités faibles ou fortes). Parmi celles-ci, la corrélation d'images numériques est une des techniques optiques [1] des plus adaptées. Ainsi, par exemple, une approche intégrée a été développée pour la mesure du facteur d'intensité des contraintes [2] pour des matériaux à comportement élastique-fragile. Les déplacements mesurés peuvent également être utilisés lors de simulations numériques à titre de comparaison, ou même comme conditions aux limites imposées. Dans les deux cas, la cohérence entre les hypothèses cinématiques faites lors de la mesure et de la simulation rendent les comparaisons plus robustes. Récemment, la méthode des éléments finis étendus (ELFE) a été introduite pour analyser des cinématiques discontinues sans remaillage [3]. Cette propriété est particulièrement séduisante lorsque des algorithmes de corrélation sont développés car les incertitudes de mesure sont d'autant plus grandes que la taille des éléments est petite [4].

L'objet de cette Note est de montrer qu'une cinématique enrichie peut être naturellement intégrée dans un algorithme de corrélation. Cette technique sera appelée "corrélation d'images numériques étendue". La démarche générale d'un algorithme de corrélation, rappelée au paragraphe 1.1, permet de considérer une large variété de champs de déplacement. Dans sa version linéarisée (3), la conservation du flot optique conduit à la résolution d'un système linéaire (5) pour déterminer les composantes inconnues associées à la base cinématique choisie. Cette dernière est peu contrainte dans la formulation générale du problème, la déclinaison particulière développée ici utilise une base d'éléments finis classique (polynomiale d'ordre un sur un support carré ou Q4P1). La décomposition enrichie (10), adaptée aux éléments finis étendus, est ensuite rappelée. Elle est implémentée dans une version (X-Q4), qui, dans cette Note, n'est illustrée que pour des discontinuités fortes lorsque la région d'étude est entièrement traversée par celles-ci (Figure 1).

L'exemple analysé concerne un assemblage boulonné de trois plaques en alliage d'aluminium (Figure 2a). Une analyse d'incertitude montre que l'enrichissement ne dégrade pas significativement celle-ci lorsque des déplacements constants sont appliqués (Figure 3-a). Par contre, lorsque les déplacements appliqués sont discontinus, le gain est significatif avec la version étendue, bien que, dans l'exemple particulier étudié, le mouchetis ne soit pas optimal (Figure 3-b). L'analyse des deux discontinuités, l'une avec un champ enrichi et l'autre sans, montre l'intérêt (Figure 2) en termes d'amplitude de résidus et de leur localisation. De plus, une sensibilité assez faible de la version X-Q4 à la taille de l'élément est observée (Figure 4).

L'algorithme discuté ici a été particularisé au cas où la discontinuité traverse toute la région d'étude. Il peut être généralisé [au sens de l'équation (10)] au cas d'une surface fissurée voire à celui de discontinuités faibles. Dans le cas présenté ici, la ligne de discontinuité a été (aisément) positionnée par l'utilisateur. A terme, une détection automatique sera implémentée.

Full-field measurements are useful when localized phenomena (i.e., weak or strong discontinuities) are observed. Digital image correlation is one of the optical techniques [1] that are used to capture these effects. For instance, an integrated approach was developed to measure stress intensity factors in elasticbrittle materials [2]. The measured displacement may be used in numerical simulations to compare both data, or even to prescribe measured quantities. In both cases, the fact that the kinematic hypotheses are kept identical allows one to be fully consistent from the experimental side (e.g., when pictures are analyzed) to the numerical one. Recently, the extended finite element method (X-FEM) was introduced to analyze discontinuous displacements without remeshing [3]. This particular feature is appealing when measurements are needed since the corresponding uncertainties increase as the element size decreases [4].

The aim of the Note is to show that the kinematics used in the extended finite element method may be used in a correlation algorithm. It corresponds to an extension of the DIC approach presented in Ref. 
[4] when enriched functions are added to the basis of displacement fields. It is referred to as "eXtended Digital Image Correlation" (X-DIC).

\section{Digital image correlation}

\subsection{General principle}

Let us consider two digital (gray level) pictures shot at two different instants of time. The reference, $f$, and the deformed state, $g$, pictures of a surface (represented here as gray level valued function of the pixel coordinates) are related by the advection of the texture in the displacement field $\mathbf{u}$

$$
g(\mathbf{x})=f(\mathbf{x}+\mathbf{u}(\mathbf{x}))
$$

From the knowledge of $f$ and $g$, the problem consists in estimating $\mathbf{u}$ as accurately as possible. The conservation of the optical flow (1) is linearized by assuming that the reference image is differentiable

$$
\Phi^{2}(\mathbf{x})=[\mathbf{u}(\mathbf{x}) \cdot \nabla f(\mathbf{x})+f(\mathbf{x})-g(\mathbf{x})]^{2}
$$

and consists in minimizing the local residual $\Phi$. To estimate $\mathbf{u}$, the quadratic difference (right hand side of Eq. (2)) is integrated over the studied domain $\Omega$ and subsequently minimized

$$
\eta^{2}=\int_{\Omega}[\mathbf{u}(\mathbf{x}) \cdot \nabla f(\mathbf{x})+f(\mathbf{x})-g(\mathbf{x})]^{2} \mathrm{~d} \mathbf{x}
$$

As such, the measurement of the displacement is an ill-posed problem. The point-wise displacement is only measurable along the direction of the intensity gradient, and thus calls for a regularization. The displacement field is decomposed over a set of functions $\Psi_{n}(\mathbf{x})$. In particular, each component of the displacement field may be treated in a similar manner, and thus only scalar functions $\psi_{n}(\mathbf{x})$ are introduced

$$
\mathbf{u}(\mathbf{x})=\sum_{\alpha, n} a_{\alpha n} \psi_{n}(\mathbf{x}) \mathbf{e}_{\alpha}
$$

where $\mathbf{e}_{\alpha}$ are elementary unit vectors along each space dimension $\alpha$ and $a_{\alpha n}$ the corresponding amplitudes. The objective function is thus a quadratic form of the unknowns $a_{\alpha n}$. Its minimization leads to a linear system

$$
\mathrm{Ma}=\mathrm{b}
$$

where $\partial_{\alpha} f=\nabla f . \mathbf{e}_{\alpha}$ denotes the directional derivative, the matrix $\mathbf{M}$ and the vector $\mathbf{b}$ read

$$
M_{\alpha n \beta m}=\int_{\Omega}\left[\psi_{m}(\mathbf{x}) \psi_{n}(\mathbf{x}) \partial_{\alpha} f(\mathbf{x}) \partial_{\beta} f(\mathbf{x})\right] \mathrm{d} \mathbf{x}
$$

and

$$
b_{\alpha n}=\int_{\Omega}[g(\mathbf{x})-f(\mathbf{x})] \psi_{n}(\mathbf{x}) \partial_{\alpha} f(\mathbf{x}) \mathrm{d} \mathbf{x}
$$

When the functions $\psi_{n}(\mathbf{x})$ are shape functions of finite elements, the proposed framework allows one to develop a correlation algorithm that is in direct link with finite element simulations. In the following, it is proposed to discuss a technique to deal with strong discontinuities. 


\subsection{Extended digital image correlation}

When discontinuous fields are sought, the previous framework is used with an enriched kinematics. If classical finite element shape functions were used, the discontinuity would be smoothed. One of the consequences may be a bias in the subsequent analysis of the displacement fields (e.g., evaluation of a stress intensity factor). The property of the partition of unity [5] of finite element shape functions over the zone covered by the set of nodes $\mathcal{N}$

$$
\sum_{n \in \mathcal{N}} N_{n}(\mathbf{x})=1
$$

is exploited to enrich the kinematic basis, where $N_{n}$ are scalar shape functions to interpolate the displacement $\mathbf{u}(\mathbf{x})$ in an element. The enriched discretization reads

$$
\mathbf{u}(\mathbf{x})=\sum_{n \in \mathcal{N}, \alpha} a_{\alpha n} N_{n}(\mathbf{x}) \mathbf{e}_{\alpha}+\sum_{n \in \mathcal{N}_{e n r}, \alpha} d_{\alpha n} N_{n}(\mathbf{x}) \varphi(\mathbf{x}) \mathbf{e}_{\alpha}
$$

where $\varphi$ is the enrichment function and $\mathcal{N}_{\text {enr }}$ is a sub-set of $\mathcal{N}$ in which nodes hold enriched degrees of freedom $d_{\alpha n}$. The enrichment function can be chosen arbitrarily to capture a specific feature of the displacement field in the minimization problem. In the following, we focus on displacement fields with strong discontinuities (e.g., cracks). For instance, the components of the displacement have a discontinuity across the crack front and a square root dependence close to the crack tip. In the original X-FEM, five enriched functions are used, namely one that is discontinuous across the crack front, $H$, and four "singular" functions, $C_{j}, j=1-4$. The approximation of the displacement becomes

$$
\mathbf{u}(\mathbf{x})=\sum_{n \in \mathcal{N}, \alpha} a_{\alpha n} N_{n}(\mathbf{x}) \mathbf{e}_{\alpha}+\sum_{n \in \mathcal{N}_{\text {cut }}, \alpha} d_{\alpha n} N_{n}(\mathbf{x}) H(\mathbf{x}) \mathbf{e}_{\alpha}+\sum_{n \in \mathcal{N}_{\text {tip }}, \alpha, j} c_{\alpha n j} N_{n}(\mathbf{x}) C_{j}(\mathbf{x}) \mathbf{e}_{\alpha}
$$

where $a_{\alpha n}, d_{\alpha n}$ and $c_{\alpha n j}$ are the unknown degrees of freedom.

\subsection{Implementation}

In the following, the previous approach is implemented in a "finite element" correlation code [4]. Q4finite elements are the simplest basis for square domains. Each element is mapped onto the square $[-1,1]^{2}$, where the four basic functions are $(1 \pm x)(1 \pm y)$ in a local $(x, y)$ frame. The displacement decomposition (4) is therefore particularized to account for the shape functions of a finite element discretization. For the enrichment, the choice proposed by Hansbo and Hansbo [6] is used (Figure 1). Each node of an element whose support is completely cut by the discontinuity holds an additional degree of freedom for each component of the displacement associated with the function $H_{e}$

$$
H_{e}(\mathbf{x})=\mathcal{H}(\mathbf{x})-\mathcal{H}\left(\mathbf{x}_{e}\right)
$$

where the vector $\mathbf{x}_{e}$ gives the location of node $e$, and $\mathcal{H}$ is the Heaviside step function. Consequently, the enrichment function $H_{e}$ is equal to 0 over the area of the support of $e$ (elements that have $e$ within their connectivity) on the same side of the crack as $e$. The main advantage of this function is that it avoids so-called blending elements (elements in which the enrichment is not supported by a partition of unity, i.e., elements that do not have all their nodes enriched). Furthermore, enriched terms of the matrix are only to be computed for the elements cut by the crack. Ill-conditioning may occur due to elements for which the enriched function is not vanishing over a small area. As a remedy, enriched degrees of freedom corresponding to nodes whose distance to the crack is about the element size are set to zero 
and not considered as unknowns of the system. Those nodes are depicted using crosses on Figure 1. The numerical integration is performed pixel by pixel and any subdividing or special quadrature for the enriched elements are not needed. However, when a discontinuous kinematics is added to an element, the elementary matrix is to be computed over two different areas of the deformed image.

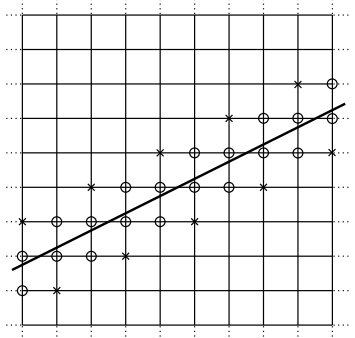

Figure 1. Discontinuous enrichment on a typical mesh. Circles denote nodes that hold discontinuous degrees of freedom, cross nodes that hold discontinuous degrees of freedom considered as fixed. Enrichissement discontinu sur un maillage. Les cercles correspondent à des degrés de liberté avec discontinuités et les croix à des degrés de liberté avec discontinuité gelés.

\section{Application to a bolted assembly}

The X-Q4 algorithm is now applied to a practical configuration corresponding to a tensile test on a bolted assembly [7]. In the experiment, there are three aluminum plates assembled by a bolt. The previous algorithm is suited for the analysis of the displacement field on the edge of the sample. The region of interest is depicted in Figure 2-a. Upon loading, the central plate may slip with respect to the other ones, giving rise to two tangential discontinuities of the displacement along the interfaces. Only one (left side) of the two discontinuities is analyzed with the extended correlation algorithm. The other one is studied with a plain Q4 algorithm, where no enrichment is used. Thus we have a direct evaluation of the performance of the proposed enrichment. In the present case, the location of the discontinuity line is (easily) chosen by the user.

Before commenting the results, it is worth analyzing the performance of the correlation algorithm. A common baseline analysis consists in prescribing known displacements to the ROI and evaluate the displacement uncertainty [4]. Two cases are considered. First, a uniform displacement ranging from 0 to 1 pixel is prescribed. This allows one to estimate both the systematic and fluctuating parts of the error in the measured displacement. The fluctuation part is typically much larger, and thus only the latter is documented here, and quantified through the standard deviation of the displacement field. It is shown for both Q4 and X-Q4 algorithms in Figure 3-a. Even though the kinematic basis of the extended algorithm is richer than in the Q4 version, the overall performance is conserved. The only difference is that it levels off earlier than the Q4 algorithm, yet at the very low value of $10^{-3}$ pixel. To capture without enrichment a rapid variation of the displacement such as a discontinuity, a small element size would be needed, thus implying a rather large uncertainty. Conversely, with enrichment, the full benefit of the very small uncertainty attached to large element sizes is preserved without any prejudice to the description of the discontinuity.

The second configuration consists in applying a sub-pixel displacement discontinuity along a prescribed line. Figure 3-b shows that extended algorithm yields better results. The displacement uncertainty increases with the element size (when an element is cut by a discontinuity, the neighboring ones are also concerned because of the continuity of the shape functions). Conversely, the extended algorithm yields uncertainties that, in the present case, are roughly independent of the element size. 


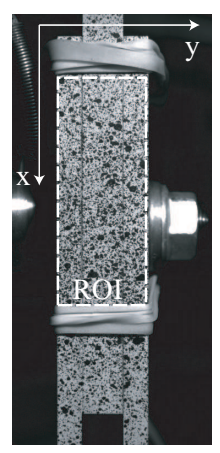

-a-

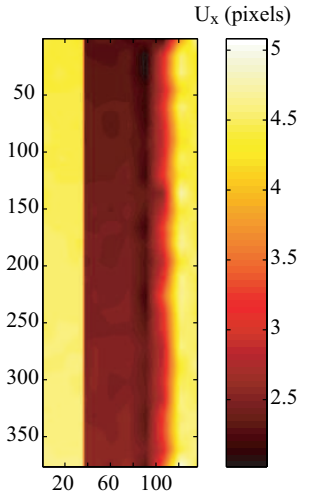

$-b-$

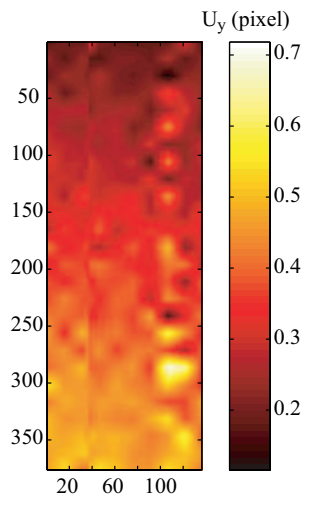

$-\mathrm{c}-$

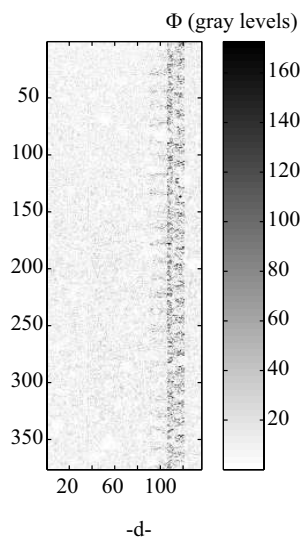

$-\mathrm{d}-$

Figure 2. -a-Analyzed bolted assembly and rectangular region of interest (ROI) delimited by a white dashed line. -b-Vertical displacement field in pixels. -c-Horizontal displacement field. -d-Gray level residual map. -a-Assemblage boulonné et région d'étude rectangulaire délimitée par un trait blanc discontinu. -b-Champ de déplacement vertical en pixels. -c-Champ de déplacement horizontal. -d-Carte de résidus en niveaux de gris.

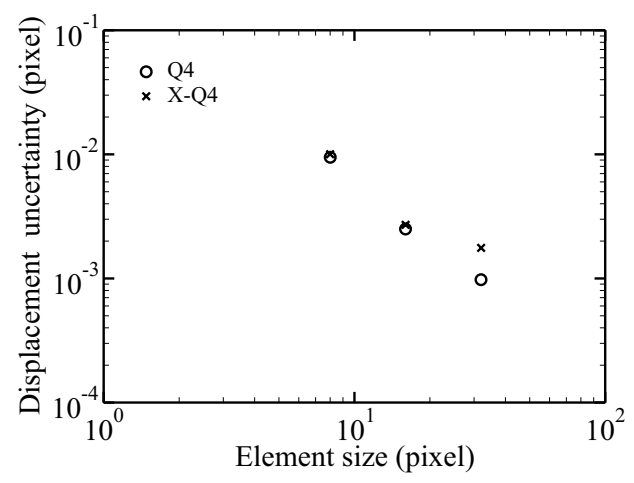

$-a-$

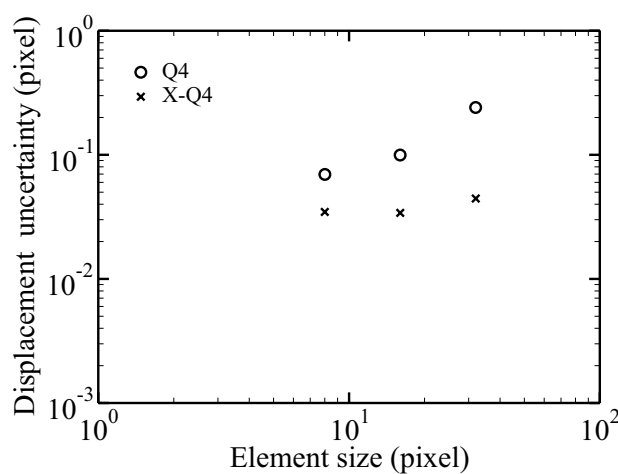

$-b-$

Figure 3. Displacement uncertainties as a function of element size for a Q4 and an extended (X-Q4) algorithm when a uniform displacement is prescribed (a), and a discontinuous displacement (b). Incertitudes en déplacement en fonction de la taille des éléments pour un algorithme $Q_{4}$ et X-Q4 lorsqu'un champ constant (a) ou discontinu (b) est imposé.

For the previous analysis, it is concluded that the displacement uncertainty is less than 0.05 pixel in the presence of a discontinuity. It is worth remembering that this result is related to the gray level distribution along the assumed discontinuity. In the present case, the latter is poor due to lighting conditions and the texture itself. When the element size is equal to 16 pixels, the displacement fields are shown in Figure 2b,c. From the error map (Figure 2-d) it is concluded that the kinematics is well described by the extended algorithm (left discontinuity), whereas, as expected, the Q4 algorithm smears out the (right) discontinuity. The fact that the random texture is poor induces displacement fluctuations that are clearly visible on the horizontal displacement map.

The same type of analysis is performed by decreasing the element size (12 pixels and 8 pixels). The left discontinuity is still analyzed with an extended algorithm whereas the right one with a Q4 algorithm. As the element size decreases, the smeared out zone decreases (Figure 4). Conversely, the displacement field 


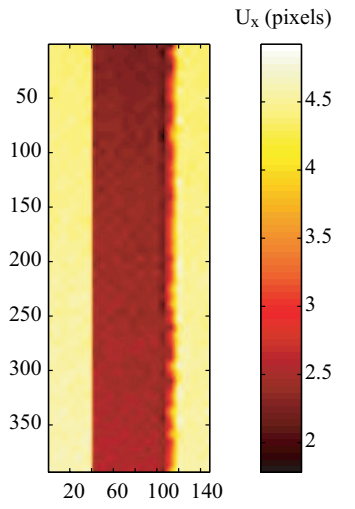

-a-

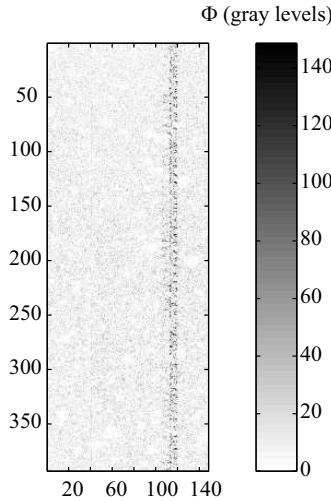

$-b-$

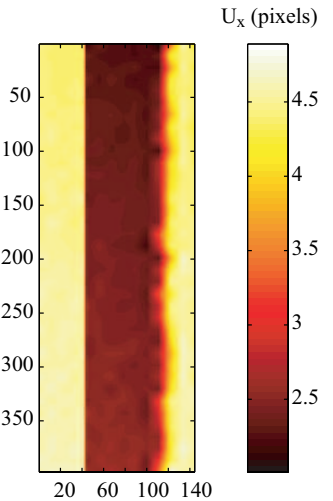

$-\mathrm{c}-$

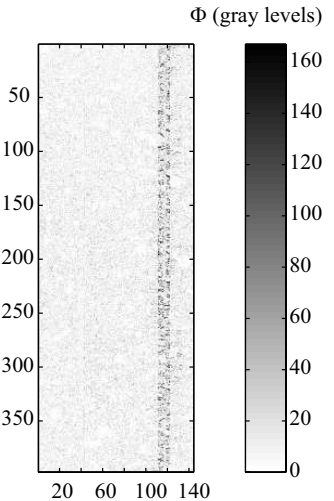

$-\mathrm{d}-$

Figure 4. Vertical displacement field in pixels and corresponding error map in gray levels when the element size is equal to 8 pixels ( $\mathrm{a}$ and $\mathrm{b}), 12$ pixels (c and d). Champ de déplacement vertical en pixels et résidus correspondants lorsque la taille d'élément est égale à 8 ( $a$ et b) ou 12 pixels (c et d).

around the left discontinuity remains almost unaltered thanks to the extended algorithm. The fact that the displacement level along the discontinuity is significantly greater than the measurement uncertainty makes the results given by the extended algorithm less sensitive to the element size than those with a Q4 algorithm.

\section{Summary and perspectives}

An extended correlation algorithm was presented in this Note. It allows one to analyze situations in which discontinuities in the displacement field arise. It is the experimental counterpart to an enriched finite element kinematics. Sub-pixel and localized discontinuities are measurable. The algorithm was applied to study an experiment on a bolted assembly for which a much more accurate kinematic description is obtained as compared to a Q4 basis without enrichment.

The approach presented herein was particularized to describe a discontinuity that traverses the whole region of interest. It can be further generalized [as already exemplified by Eqn. (10)] to the analysis of cracked surfaces or even to the case of weak discontinuities. Furthermore, an automatic detection and optimization of the discontinuity geometry is desirable and will be presented in a forthcoming communication.

\section{Acknowledgements}

This work is part of a project (PHOTOFIT) funded by the Agence Nationale de la Recherche. The authors wish to thank Stéphane Guinard, Nicolas Swiergiel and Julien Vignot of EADS for providing the pictures of the bolted assembly analyzed herein. 


\section{References}

[1] P.K. Rastogi, ed., Photomechanics, Springer, Berlin (Germany), (2000).

[2] F. Hild, S. Roux, Measuring stress intensity factors with a camera: Integrated Digital Image Correlation (I-DIC), C.R. Mecanique 334 (2006) 8-12. See also, S. Roux, F. Hild, Stress intensity factor measurements from digital image correlation: post-processing and integrated approaches, Int. J. Fract. 140 (2006) 141-157.

[3] N. Möes, J. Dolbow, T. Belytschko, A finite element method for crack growth without remeshing, Int. J. Num. Meth. Eng. 46 (1999) 133-150.

[4] G. Besnard, F. Hild, S. Roux, "Finite-element" displacement fields analysis from digital images: Application to PortevinLe Châtelier bands, Exp. Mech. 46 (2006) 789-803.

[5] I. Babuska, J.M. Melenk, The partition of unity method, Int. J. Num. Meth. Eng. 40 (1997) 727-758.

[6] A. Hansbo, P. Hansbo, A finite element method for the simulation of strong and weak discontinuities in solid mechanics, Comp. Meth. Appl. Mech. Eng. 193 (2004) 3523-3540.

[7] S. Guinard, N. Swiergiel, J. Vignot, Personal communication, 2006. 